\title{
Improving health-related quality of life through an evidence-based obesity reduction program: the Healthy Weights Initiative
}

This article was published in the following Dove Press journal:

Journal of Multidisciplinary Healthcare

7 March 2016

Number of times this article has been viewed

\author{
Mark E Lemstra' \\ Marla R Rogers ${ }^{2}$ \\ 'Alliance Health, Moose Jaw, \\ ${ }^{2}$ Department of Physical Medicine \\ and Rehabilitation, College of \\ Medicine, University of Saskatchewan, \\ Saskatoon, SK, Canada
}

\begin{abstract}
When evaluating any health intervention, it is critical to include the impact of the intervention on health-related quality of life (HRQL). Among those who are obese, HRQL is often lower than the general population and even more when considering obesity-related comorbidities and bodily pain. The objectives of this paper were to determine the impact of a multidisciplinary, community-based obesity reduction program on HRQL and to determine the independent risk factors for lack of improvement from baseline to follow-up. HRQL was measured using the Medical Outcomes Study 36-Item Short-Form Health Survey (SF-36) at baseline and follow-up ( 24 weeks). To date, $84.5 \%$ of those who completed the program had improvements in their overall SF-36 score. Significant increases in the mean scores on eight dimensions of health were also observed. Lack of improvement was independently affected by smoking status (odds ratio 3.75; 95\% confidence interval 1.44-9.78; $P=0.007$ ) and not having a buddy to attend the program (odds ratio $3.70 ; 95 \%$ confidence interval $1.28-10.68 ; P=0.015$ ). Obesity reduction programs that target increasing exercise, improving diet, and cognitive behavioral therapy can positively impact HRQL in obese adults. Social support has a strong role to play in improving outcomes.
\end{abstract}

Keywords: obesity, health-related quality of life, social- support, SF-36, Canada

\section{Introduction}

With a seemingly ever-increasing global prevalence rate of obesity, it has never been more important to evaluate the impact of this condition on an individual and on society as a whole. The physical health risks associated with obesity have been widely studied ${ }^{1-16}$ but just as important are the emotional and psychological risks that exist. ${ }^{17,18}$ There have been a number of studies that have looked at obesity and health-related quality of life (HRQL), ${ }^{19-21}$ which is particularly important to measure, as it can quantify not only the physical but also the psychological and social well-being of a person. These broader qualities of HRQL are closely aligned to the World Health Organization's definition of health ${ }^{22}$ and can effectively capture a range of states of disease to well-being. ${ }^{23}$

When compared to the general adult population or with age- and sex-matched controls, those with obesity (body mass index $[\mathrm{BMI}] \geq 30$ ) have significantly lower HRQL. ${ }^{24,25}$ Physical and mental well-being may be affected more by those with obesity who also suffer bodily pain or from other comorbidities. A population-based survey of 155,989 American adults found that obesity increased the risk of poor physical and mental health outcomes, but once pain and obesity-related comorbidities were removed from the model, the adjusted risks decreased significantly. ${ }^{26}$ Another study found that 
the presence of comorbidities strongly affects emotional wellbeing in those with obesity, ${ }^{27}$ while yet another study found that obese persons with pain report the greatest impairments in overall health. ${ }^{28}$

Treating obesity with clinical interventions in the past has shown that it is possible to improve HRQL through weight loss. For example, a randomized trial of a clinical weight loss program found that participants scored lower than agespecific population norms on HRQL at baseline, but those who completed the intervention improved in physical functioning, general health, vitality, and mental health. Furthermore, in those participants who regained some of the weight at 2-year follow-up, HRQL improvements were maintained. ${ }^{29}$ Studies of other obesity treatments, such as surgical intervention studies, have found similar improvements. ${ }^{21}$ Results from a meta-analysis of 54 studies containing nearly 100,000 participants suggested that the additional body weight alone that these individuals carried was not enough to explain lower HRQL scores than those not seeking surgical treatment. Lower scores were likely explained by the negative effect the presence of comorbidities has on quality of life. ${ }^{21}$

HRQL can be improved through various weight loss interventions. For those seeking nonsurgical treatment for obesity, many options exist (eg, various diets, behavioral therapies, exercise interventions, pharmacotherapy, commercial weight loss programs), ${ }^{30}$ but attending these programs may be met with cost and accessibility barriers or may fail to provide the necessary support to adhere to the program. One way to improve access and adherence - and therefore, provide an opportunity to lose more weight and improve HRQL - is to use a free or low-cost community-based obesity reduction program with a strong emphasis on social support.

The Healthy Weights Initiative (HWI) is a free, multidisciplinary, community-based obesity reduction program that uses evidence-based strategies and strongly emphasizes social support as a key to adherence and better outcomes. Prior to starting the HWI, 153 community consultations took place in the city. Prior to its implementation, every family doctor, cardiologist, and internist in the city, as well as the medical health officer of the health region, provided letters of support. The Mayor, the City Manager, the Chief of Police, both provincial Members of the Legislative Assembly, the local federal Member of Parliament, and the federal Minister of Health also provided letters of support. Additional letters of support were also provided by the Regional Intersectoral Committee (all local government agencies such as the school boards), the Healthy Active Living Committee, the In Motion Committee, not-for-profit organizations such as the Young
Men's Christian Association (YMCA), key businesses such as the Credit Union and the Co-op, the Chamber of Commerce, the Heart and Stroke Foundation, the Canadian Cancer Society, and the Public Health Agency of Canada. In total, 71 letters of support were obtained.

The Initiative was designed to follow the ten evidencebased principles included in the International Obesity Task Force guidelines for long-term obesity reduction. ${ }^{31}$ The objectives of this study were to determine the impact of the HWI on HRQL and to determine the adjusted risk factors for lack of improvement from baseline to follow-up on the overall score of the Medical Outcomes Study 36-Item Short-Form Health Survey (SF-36).

\section{Methods}

\section{Setting}

The HWI took place in Moose Jaw, Saskatchewan, Canada. The city has a population of 33,274 , with a prevalence of adult obesity of $26.3 \% .^{32}$ The program itself was delivered by a wellness and rehabilitation clinic in the city and took place at the local YMCA.

\section{Ethics}

The study meets the requirements for exemption status per Article 2.5 of the Tri-Council Policy Statement: Ethical Conduct for Research Involving Humans, December 2014. This study was an evaluation of a real-world program, and not a research study. As such, participants provided implied consent with the completion of the survey.

\section{Participants}

Obese (BMI $\geq 30$ ) adults who were referred by a medical doctor were eligible to participate. All participants received a medical screen by their physician to ensure they could safely participate.

\section{Measures}

The medical screen included measurements of blood pressure, blood sugar, and blood cholesterol. Each participant also underwent a fitness evaluation that included calculation of BMI, waist-to-hip ratio, body fat percentage, and aerobic fitness. ${ }^{33}$ HRQL was measured using the SF-36. ${ }^{34}$ The SF-36 is a brief, psychometrically sound measure of quality of life that provides scores on eight dimensions of health (physical functioning, limits due to physical health, pain, general health, vitality, social functioning, limits due to emotional health, and emotional well-being), with lower scores indicating lower quality of life in each dimension. It 
has been considered the "generic measure of choice in obesity research" by the United States Task Force on Developing Obesity Outcomes and Learning Standards (TOOLS). ${ }^{35}$

Four questions to measure self-esteem were also included. These were taken from the Self-Description Questionnaire III and asked participants to give an answer of false; mostly false; sometimes true, sometimes false; mostly true; or true to each statement. These statements were 1) In general, I like the way I am, 2) Overall, I have a lot to be proud of, 3) A lot of things about me are good, and 4) I like the way I look. ${ }^{36}$

Depressed mood was measured using the Beck Depression Inventory II. ${ }^{37}$ This tool has a good internal scale reliability for community-dwelling adults (Cronbach's alpha = $0.86-0.92) .^{38}$

Participants also answered questions related to demographics, presence of comorbidities, and smoking status.

\section{Procedures}

The program was provided free of cost for all participants, and each received group-based programming for 12 weeks, including five group exercise sessions per week led by an exercise therapist, one dietary session per week led by a dietician, and one cognitive behavioral therapy (CBT) session led by a registered psychologist. After the initial 12 weeks, participants received one group-based exercise session per week for an additional 12 weeks for maintenance.

In order to promote strong social support, each participant was asked to attend with a "buddy": a friend or family member who also had a BMI $\geq 30$. This "buddy", along with two others, was also asked to sign a social support contract, which acknowledged each participant's physical activity and dietary goals, possible barriers to these goals, and solutions to overcome the barriers. These social support components were put in place as recommended by the Canadian Society for Exercise Physiology Physical Activity Training for Health guidelines. ${ }^{33}$ At 24 weeks, participants completed identical measures from baseline.

\section{Analysis}

Using SPSS 22.0, mean scores of each SF-36 dimension were compared before and after the program using paired samples $t$-tests $(P<0.05)$. Differences in scores were compared to determine who improved across each dimension (as defined as an increase in score of one point or more) and those who did not (as defined as no increase or a decrease in score). An overall improvement on SF-36 indicated improvement in HRQL for this study.
Mean changes in weight and body composition were compared between those who had improved in overall HRQL versus those who did not, using one-way analysis of variance.

Cross-tabulations were then performed to determine significant associations between those who improved in HRQL and those who did not, across demographic variables, presence of comorbidities, program adherence, self-esteem, smoking status, depressed mood, and social support. Significant differences were determined using chi-square test $(P<0.05)$. The unadjusted effect of each covariate was determined and then entered one step at a time based on changes in the $-2 \log$ likelihood and the Wald test. The final results are presented as adjusted odds ratios with $95 \%$ confidence intervals (CIs).

\section{Results}

From January 2014 to March 2015, 290 participants started the program and 234 participants completed the program $(80.7 \%)$. The majority of participants were female $(73.1 \%)$, middle-aged (45-64 years, 52.1\%), with $6.4 \%$ between the ages of 18 years and 25 years; $15.4 \%$ between the ages of 26 years and 34 years; and $24.8 \%$ between the ages of 35 years and 44 years. Another $1.3 \%$ was $>65$ years. Slightly over a quarter of participants were single (27.4\%), with $62.8 \%$ reporting being married and $9.8 \%$ reporting a common-law relationship. Most were employed, with 20.9\% in a professional occupation and $62.8 \%$ in a nonprofessional occupation. The majority had received postsecondary education, with $59.3 \%$ completing university, college, or a trade. Only $31.9 \%$ of participants did not report any comorbidities, while $10.8 \%$ reported three or more. Smokers made up $14.3 \%$, and $45.7 \%$ had depressed mood as determined by the Beck Depression Inventory II. With regard to social support, $87.2 \%$ attended the program with a buddy and $35.3 \%$ of participants had their buddy sign the social support contract.

Among those who completed the program, 84.5\% had improved HRQL as determined by an increase in overall SF-36 score. Table 1 shows the mean scores at baseline and at follow-up on the eight dimensions, as well as the absolute (baseline score subtracted from follow-up score) and relative change (100 - [baseline score/follow-up score]). A higher score on each dimension represented an improvement in quality of life. Improvements were observed across all eight dimensions in terms of mean score.

Looking at each dimension independently, Table 2 reports the percentage of participants who had an improved score from baseline to follow-up on each dimension. Improvements 
Table I Healthy Weights Initiative - SF-36 dimensions ( $N=209)$

\begin{tabular}{|c|c|c|c|c|c|}
\hline & Baseline, mean (SD) & Follow-up, mean (SD) & Absolute change & Relative change (\%) & $P$-value \\
\hline Physical functioning & $65.9(22.0)$ & $78.0(17.4)$ & +12.1 & 15.5 & 0.000 \\
\hline $\begin{array}{l}\text { Less role limitations due to } \\
\text { physical health }\end{array}$ & $61.8(35.6)$ & $74.4(33.3)$ & +12.6 & 16.9 & 0.000 \\
\hline Pain & $63.8(22.5)$ & $70.0(2 I .1)$ & +6.2 & 8.9 & 0.000 \\
\hline General health & $5 \mathrm{I} .2(2 \mathrm{I} .3)$ & $64.1(19.6)$ & +12.9 & 20.1 & 0.000 \\
\hline Vitality & $43.3(17.7)$ & $61.3(18.1)$ & +18.0 & 29.4 & 0.000 \\
\hline Social functioning & $71.1(24.1)$ & $79.5(18.2)$ & +8.4 & 10.6 & 0.000 \\
\hline $\begin{array}{l}\text { Less role limitations due to } \\
\text { emotional health }\end{array}$ & $68.7(34.9)$ & $76.5(30.4)$ & +7.8 & 10.2 & 0.000 \\
\hline Emotional well-being & $64.3(18.6)$ & $73.7(\mid 3.2)$ & +7.6 & 12.8 & 0.000 \\
\hline
\end{tabular}

Notes: Higher scores indicate improvements on that dimension. SF-36 is the Medical Outcomes Study 36-Item Short-Form Health Survey. Abbreviation: SD, standard deviation.

were observed from $47 \%$ to $83 \%$ of participants across separate dimensions. Although those who improved in HRQL lost more weight and body fat in comparison to those who did not improve, these differences were not statistically significant (data not shown).

After cross-tabulation, there were no statistically significant differences in overall SF-36 score improvement and sex, age, marital status, employment status, program attendance ( $\geq 80 \%$ versus $<80 \%$ attendance), presence of comorbidities, or depressed mood at baseline. Overall improvement in HRQL was associated with smoking status at baseline (only $70 \%$ of smokers had improved scores, while $86.9 \%$ of nonsmokers had improved scores). Improvement in HRQL was also associated with whether a buddy attended the program; $86.3 \%$ of those who had a buddy in the program had improved HRQL versus $70.8 \%$ of those who did not have a buddy $(P=0.048)$. Negative responses (false; mostly false; or sometimes true, sometimes false) on all four self-esteem questions at baseline were associated with improved HRQL. The number of comorbidities reported by participants had a weak, but significant, negative correlation with SF-36 baseline scores (Pearson's $r=-0.315 ; P<0.001$ ). The relationship was even weaker with SF-36 follow-up scores (Pearson's $r=-0.232 ; P=0.001)$.

Table 2 Percentage of participants whose SF-36 dimensional score improved from baseline to follow-up

\begin{tabular}{ll}
\hline & Improved (\%) \\
\hline Physical functioning & 71.3 \\
Role limits due to physical health & 59.4 \\
Pain & 50.7 \\
General health & 76.6 \\
Vitality & 83.3 \\
Social functioning & 47.4 \\
Role limits due to emotional health & 76.3 \\
Emotional well-being & 72.7
\end{tabular}

Note: SF-36 represent the Medical Outcomes Study 36-Item Short-Form Health Survey.
After logistic regression, smoking status increased the risk of no improvement on overall SF-36 after the program (odds ratio 3.75; 95\% CI 1.44-9.78; $P=0.007$ ). Additionally, not having a buddy in the program increased the risk of no improvement on overall SF-36 by $270 \%$ (95\% CI 1.28-10.68; $P=0.015)$. Self-esteem was determined to be a confounder during regression analysis and, as such, was controlled for in the final regression model. These results are presented in Table 3.

\section{Discussion}

After attending 24 weeks of the HWI, 84.5\% of participants reported improvements in HRQL as reflected in overall SF-36 score. Absolute and relative improvements in mean scores across each dimension from baseline to follow-up were also observed, with the largest improvements observed for vitality, general health, role limitations due to physical health, and physical functioning. Although mean scores on each dimension improved, they were still lower than normative scores from the general Canadian population..$^{39}$ In comparison to other obese populations, the dimensional mean scores at follow-up in the study group were comparable to or better than the mean scores found in general obese populations and among obese individuals seeking conservative treatments. ${ }^{21}$ The HWI is a multidisciplinary, evidence-based program that strongly promotes social support as an important component of positive lifestyle change. The weight loss components include group-based exercise sessions, dietary sessions, and CBT sessions. Physical activity has been associated with improvements in quality of life in a number of studies and patient populations, including elderly adults, healthy adults, and adults with various clinical conditions, ${ }^{40}$ as well as among obese populations. ${ }^{41}$ An American study found that those adults who achieved recommended daily physical activity levels had a significantly reduced risk for unhealthy days, 
Table 3 Independent risk factors for not improving overall SF-36 score from baseline to follow-up

\begin{tabular}{llll}
\hline & Odds ratio & $\mathbf{9 5 \%} \mathbf{C l}$ & $P$-value \\
\hline $\begin{array}{l}\text { Smoking status (baseline) } \\
\quad \text { Smoker }\end{array}$ & 3.75 & $1.44-9.78$ & 0.007 \\
$\begin{array}{l}\text { Social support } \\
\quad \text { No buddy in program }\end{array}$ & 3.70 & $1.28-10.68$ & 0.015 \\
\hline
\end{tabular}

Notes: Reference categories: smoking status - nonsmoker; social support - buddy attended program. SF-36 represent the Medical Outcomes Study 36-Item Short-Form Health Survey.

Abbreviation: $\mathrm{Cl}$, confidence interval.

even among those with chronic conditions. ${ }^{42}$ One review out of England found that higher levels of physical activity are associated with better HRQL, regardless of whether physical activity was objectively or subjectively reported. ${ }^{43}$ Diet can also play a significant role in HRQL. For example, a study of 11,015 participants and 4 years' worth of follow-up found a significant direct association between adherence to a Mediterranean diet and HRQL as measured with the SF-36, even after controlling for a number of variables. Largest improvements were seen in that of general health and vitality. ${ }^{44}$ Finally, CBT has been associated with improved quality of life in a number of patient populations in the past, including (but not limited to) musculoskeletal disorders, ${ }^{45} \mathrm{HIV},{ }^{46}$ breast cancer, ${ }^{47}$ obesity in children, ${ }^{48}$ and obesity in adults. ${ }^{49}$

It is not surprising that smoking status was an independent risk factor for keeping HRQL low. Even light smokers and ex-smokers have been found to have lower HRQL than nonsmokers, with heavy smokers scoring significantly lower in both general health and emotional health. ${ }^{50}$ Although there were not many smokers in the study sample, those who did were at risk of not improving or worsening in HRQL.

Not having a program buddy independently increased the risk of HRQL lack of improvement among those who completed the program. Those without a buddy had statistically significantly lower mean follow-up scores on physical functioning, role limitations due to physical health, pain, social functioning, and emotional well-being than those who had a buddy to attend the program. In a previous analysis of the study data, it was also found that not having social support (via buddy signing the social support contract) independently increased the risk of not completing the program. ${ }^{51}$ As such, for the duration of the program, it is now mandatory to attend the program with a buddy to ensure adherence to the program and better outcomes.

Social support is paramount to success, whether this success was measured by completing the program or by improvements in physical and emotional health. Further, social supports may play a role in mediating risk of lower HRQL in obese populations. For example, a study of obese adults from Germany found that HRQL was not impaired among males with strong social support, but this protective effect was not found in females. This may speak to the broader findings that poor mental health outcomes, such as depression, are more common in females with obesity than males with obesity. ${ }^{52}$

Another surprising finding was that there were no differences in mean HRQL scores at follow-up among those reporting comorbidities and those with no comorbidities. As stated earlier, previous research indicated that those with comorbid obesity often have lower HRQL scores than those without. ${ }^{26,27}$ There was only a weak, albeit significant, association between baseline SF-36 scores and number of comorbidities reported by participants. The presence of comorbidities appears to have less of an impact on SF-36 scores at follow-up.

\section{Limitations}

The long-term (1-year) results of the study are not yet available. It is possible that adherence to weight loss practices promoted in the program may change over time, and therefore, the physical and mental health outcomes associated with the program may also change.

\section{Conclusion}

The HWI uses evidence-based practices, is comprehensive in its targeting of unhealthy weight behaviors, is communitybased, and promotes strong social support. This program was designed specifically as an obesity reduction program, but to date there have been additional benefits to mental health and HRQL. Improved HRQL is an important outcome as it is a subjective measure of physical and emotional well-being that can be used to describe overall health.

\section{Acknowledgments}

Special thanks to Alliance Wellness and Rehabilitation and to the Moose Jaw YMCA for administering the program and collecting the data. Funding was obtained from the Public Health Agency of Canada (1516-HQ-000036). The views expressed herein do not necessarily represent the views of the Public Health Agency of Canada.

\section{Disclosure}

The authors report no conflicts of interest in this work. 


\section{References}

1. Must A, Spadano J, Coakley EH, Field AE, Colditz G, Dietz WH. The disease burden associated with overweight and obesity. JAMA. 1999;282(16):1523-1529.

2. Kopelman P. Health risks associated with overweight and obesity. Obes Rev. 2007;8(S1):13-17.

3. Hubert HB, Feinleib M, McNamara PM, Castelli WP. Obesity as an independent risk factor for cardiovascular disease: a 26-year follow-up of participants in the Framingham Heart Study. Circulation. 1983;67:968-977.

4. Van Dam RM, Li T, Spiegelman D, Franco OH, Hu FB. Combined impact of lifestyle factors on mortality: prospective cohort study in US women. BMJ. 2008;337:a1440.

5. Adams KF, Scatzkin A, Harris TB, et al. Overweight, obesity and mortality in a large prospective cohort of persons 50 to 71 years old. N Engl J Med. 2006;255(8):763-778.

6. Calle EE, Thun MJ, Petrelli JM, Rodriguez C, Heath CW Jr. Body mass index and mortality in a prospective cohort of US adults. NEngl J Med. 1999;341(15):1097-1105.

7. Flegal KM, Graubard BI, Wiliamson DF, Gail MH. Excess deaths associated with underweight, overweight and obesity. JAMA. 2005;293(15):1861-1867.

8. Fontaine KR, Redden DT, Wang C, Westfall AO, Allison DB. Years of life lost due to obesity. JAMA. 2003;289(2):187-193.

9. Olshansky SJ, Passaro DJ, Hershow RC, et al. A potential decline in life expectancy in the United States in the 21 st century. $N$ Engl J Med. 2010;170(15):1293-1301.

10. Jacobs EJ, Newton CC, Wang Y, et al. Waist circumference and all-cause mortality in a large US cohort. Arch Intern Med. 2010;170(15):1293-1301.

11. Manson JE, Stampfer MJ, Colditz GA. A prospective study of obesity and risk of coronary heart disease in women. $N$ Engl J Med. 1990;322(13):882-889.

12. De Koning L, Merchant AT, Pogue J, Anand SS. Waist circumference and waist-to-hip ratio as predictors of cardiovascular events: metaregression analysis of prospective studies. Eur Heart J. 2007;28(7): $850-856$.

13. Anderson JW, Kendall CWC, Jenkins DJA. Importance of weight management in type 2 diabetes: review with meta-analysis of clinical studies. J Am Coll Nutr. 2003;22(5):331.

14. Calle EE, Rodriguez C, Walker-Thurmond K, Thun MJ. Overweight, obesity, and mortality from cancer in a prospectively studied cohort of U.S. adults. $N$ Engl J Med. 2003;348(17):1625-1638.

15. Ligibel JA, Alfano CM, Courneya KS, et al. American society of clinical oncology position statement on obesity and cancer. J Clin Oncol. 2014;32(31):3568-3574.

16. Reeves GK, Pirie K, Beral V, et al; Million Women Study Collaboration. Cancer incidence and mortality in relation to body mass index in the Million Women Study: cohort study. BMJ. 2007;335(7630):1134.

17. Gatineau M, Dent M. Obesity and Mental Health. Oxford: National Obesity Observatory; 2011.

18. Markowitz S, Friedman MA, Arent SM. Understanding the relation between obesity and depression: causal mechanisms and implications for treatment. Clin Psychol Sci Pract. 2008;15:1-20.

19. Hassan MK, Joshi AV, Madhavan SS, Amonkar MM. Obesity and healthrelated quality of life: a cross-sectional analysis of the US population. Int J Obes Relat Metab Disord. 2003;27:1227-1232.

20. Katz DA, Mc Horney CA, Atkinson RL. Impact of obesity on healthrelated quality of life in patients with chronic illness. J Gen Intern Med. 2000;15(11):789-796.

21. van Nunen AMA, Wouters EJM, Vingerhoets AJJM, Hox JJ, Geenen R. The health-related quality of life of obese persons seeking or not seeking surgical or non-surgical treatment: a meta-analysis. Obes Surg. 2007; 17:1357-1366.

22. World Health Organization. Preamble to the Constitution of the World Health Organization as adopted by the International Health Conference, New York, NY, June 1946.
23. Ware JE. Standards for validating health measures: definition and content. J Chronic Dis. 1987;40:473-480.

24. Jia H, Lubetkin EI. The impact of obesity on health-related quality-of-life in the general US population. J Public Health. 2005;27(2):156-164.

25. Anandacoomarasamy A, Caterson ID, Leibman S, et al. Influence of BMI on health-related quality of life: comparison between an obese adult cohort and age-matched population norms. Obesity. 2009; 17:2114-2118.

26. Heo M, Allison DB, Faith MS, Zhu S, Fontaine KR. Obesity and quality of life: mediating effects of pain and comorbidities. Obes Res. 2003;11(2):209-216.

27. Doll HA, Petersen SEK, Stewart-Brown SL. Obesity and physical and emotional well-being: associations between body mass index, chronic illness, and the physical and mental components of the SF-36 questionnaire. Obes Res. 2000;8(2):160-170.

28. Barofsky L, Fontaine KR, Cheskin LJ. Pain in the obese: impact on health-related quality-of-life. Ann Behav Med. 1998;19:408-410.

29. Blissmer B, Riebe D, Dye G, Ruggiero L, Greene G, Caldwell M. Health-related quality of life following a clinical weight loss intervention among overweight and obese adults: intervention and 24 month follow up effects. Health Qual Life Outcomes. 2006;4:43.

30. Laddu D, Dow C, Hingle M, Thomson C, Going S. A review of evidence-based strategies to treat obesity in adults. Nutr Clin Pract. 2011;26(5):512-525.

31. Kumanyika S, Jeffery RW, Morabia A, Ritenbaug C, Antipatis VJ. Public health approaches to the prevention of obesity (PAHPO) Working Group of the International Obesity Task Force (IOTF). Int J Obes. 2002;26:425-436.

32. Statistics Canada [homepage on the Internet]. Canadian Community Health Survey; 2013. Statistics Canada [Online]. Available from: http://www.statcan.gc.ca/daily-quotidien/140612/dq140612b-eng.htm. Accessed December 10, 2014.

33. Canadian Society for Exercise Physiology. Physical Activity Training for Health-Resource Manual. Ottawa, ON: Canadian Society for Exercise Physiology; 2013.

34. Ware JE, Kosinski M, Keller SD. SF-36 Physical and Mental Health Summary Scales: A Users 'Manual. Boston, MA: The Health Institute; 1994.

35. Kolotkin RL, Meter K, Wiliams GR. Quality of life and obesity. Obes Rev. 2001;2:219-229.

36. Marsh HW, O’Neill R. Self description questionnaire III: the construct validity of multidimensional self-concept ratings by late adolescents. J Educ Meas. 1984;21(2):153-174.

37. Beck AT, Steer RA, Brown GK. Manual for the Beck Depression Inventory-II. San Antonio, TX: Psychological Corporation; 1996.

38. Segal DL, Coolidge FL, Cahill BS, O’Riley AA. Psychometric properties of the beck depression inventory-II (BDI-II) among communitydwelling older adults. Behav Modif. 2008;32(1):3-20.

39. Hopman WM, Towheed T, Anastassiades T, et al. Canadian normative data for the SF-36 health survey. CMAJ. 2000;163(3):265-271.

40. Pucci GC, Rech CR, Fermino RC, Reis RS. Association between physical activity and quality of life in adults. Rev Saude Publica. 2012;46(1):166-179.

41. Jepsen R, Aadland E, Andersen JR, Natvig GK. Associations between physical activity and quality of life outcomes in adults with severe obesity: a cross-sectional study prior to the beginning of a lifestyle intervention. Health Qual Life Outcomes. 2013;5(11):187.

42. Brown DW, Balluz LS, Heath GW, et al. Associations between recommended levels of physical activity and health-related quality of life findings from the 2001 behavioral risk factor surveillance system (BRFSS) survey. Prev Med. 2003;37(5):520-528.

43. Anokye NK, Trueman P, Green C, Pavey TG, Taylor RS. Physical activity and health-related quality of life. BMC Public Health. 2012;12:624-631.

44. Sanchez PH, Ruano C, de Irala J, Ruiz-Canela M, Martinez-Gonzalez MA, Sanchez-Villegas A. Adherence to the Mediterranean diet and quality of life in the SUN project. Eur J Clin Nutr. 2012;66:360-368. 
45. Castro MM, Daltro C, Kraychete DC, Lopes J. The cognitive behavioural therapy causes an improvement in quality of life in patients with chronic musculoskeletal pain. Arg Neuropsiquiatr. 2012;70(11):864-868.

46. Molassiotis A, Callaghan P, Twinn SF, Lam SW, Chung WY, Li CK. A pilot study of effects of cognitive-behavioral group therapy and peer support/counseling in decreasing psychologic distress and improving quality of life in Chinese patients with symptomatic HIV disease. AIDS Patient Care STDS. 2002;16(2):83-96.

47. Wojtyna E, Zycinska J, Stawiarska P. The influence of cognitivebehaviour therapy on quality of life and self-esteem in women suffering from breast cancer. Rep Pract Oncol Radiother. 2007;12(2):109-117.

48. Vos RC, Huisman SD, Houdijk E, Pijl H, Wit JM. The effect of family-based multidisciplinary cognitive behavioural treatment on health-related quality of life in childhood obesity. Qual Life Res. 2012;21(9):1587-1594.
49. Marchesini G, Natale S, Chierici S, et al. Effects of cognitive-behavioural therapy on health-related quality of life in obese subjects with and without binge eating disorder. Int J Obes. 2002;26(9):1261-1267.

50. Wilson D, Parsons J, Wakefield M. The health-related quality of life in never smokers, ex-smokers, light, moderate, and heavy smokers. Prev Med. 1999;29(3):139-144.

51. Lemstra M, Rogers M. The importance of community consultation and social support in adhering to an obesity reduction program: results from the healthy weights initiative. Patient Prefer Adherence. 2015;9:1473-1480.

52. Wiczinski E, Doring A, John J, von Lengerke T; KORA Study Group. Obesity and health-related quality of life: does social support moderate existing associations? Br J Health Psychol. 2009;14(4):717-734.
Journal of Multidisciplinary Healthcare

\section{Publish your work in this journal}

The Journal of Multidisciplinary Healthcare is an international, peerreviewed open-access journal that aims to represent and publish research in healthcare areas delivered by practitioners of different disciplines. This includes studies and reviews conducted by multidisciplinary teams as well as research which evaluates the results or conduct of such teams or

\section{Dovepress}

healthcare processes in general. The journal covers a wide range of areas and welcomes submissions from practitioners at all levels, from all over the world. The manuscript management system is completely online and includes a very quick and fair peer-review system. Visit http://www.dovepress.com/testimonials.php to read real quotes from published authors.

Submit your manuscript here: http://www.dovepress.com/journal-of-multidisciplinary-healthcare-journal 